\title{
IN FLUÊNCIA DA FUMONISINA SOBRE A RESPOSTA IMUNOLÓGICA DE AVES: revisão bibliográfica
}

\author{
F umonisin influence in the immune response of poultry: bibliographical review
}

\author{
Luiz Rodolfo Scavazza Gertnera, E lizabeth Santin ${ }^{\mathrm{b}}$, Marina Bolzani Saad ${ }^{\mathrm{c}}$ \\ a Médico Veterinário, Mestrando em Patologia Veterinária(UFPR), Curitiba, PR - Brasil, e-mail: Irgertner@ yahoo.com.br \\ b Médica Veterinária, Mestranda em PatologiaV eterinária(UFPR), Curitiba, PR - Brasil, e-mail: marina bolzani@ yahoo.com.br \\ ${ }^{c}$ Médica Veterinária, Professora A djunta de O rnitopatologia (UFPR), Curitiba, PR - Brasil, e-mail: santin@ ufpr.br
}

\begin{abstract}
Resumo
0 crescimento fúngico e a subsequente contaminação de produtos destinados à alimentação animal e humana por toxinas produzidas pelos fungos representam não só risco econômico, ao influenciar negativamente no desenvolvimento dos cereais e não apresentar o valor nutritivo adequado e, como também, para a saúde, podendo ocasionar micotoxicoses nos animais pela ingestão de cereais, contaminados e nos seres humanos expostos, tanto pelo consumo de cereais quanto pelo consumo de produtos animais contaminados, como leite, carne e ovos. As fumonisinas, produzidas pelos fungos $F$ usarium moniliforme e F . proliferatum, são uma família de micotoxinas que podem contaminar os alimentos, predominantemente à base de milho. Nas espécies aviárias, as fumonisinas têm associação, principalmente, com redução no desempenho, mas podem causar severa imunossupressão, afetando células e órgãos do sistema imune.
\end{abstract}

Palavras-chave: Fusarium; Toxinas; Sistema imune.

\begin{abstract}
The mould growth and the subsequent contamination by toxins produced by molds of products destined to animal and human feed represent economic risk, influencing negative by the development of cereals and not presenting the adjusted nutritional value that healthful cereals can provide, besides presenting health risk, being able to cause mycotoxicosis in animals for the ingestion of contaminated cereals, and in human beings for consumption of cereals and also consumption of animal products, as milk, meat and eggs. The fumonisins, produced by molds Fusarium moniliforme and F. proliferatum, are a family of mycotoxins that can contaminate foods, predominantly in cereal products. In poultry species the fumonisins have association, mainly, with reduced performances, but they can cause also severe immunosuppression, affecting cells and organs of the immune system.
\end{abstract}

Keywords: Fusarium; Toxins; Immune system.

Rev. Acad., Ciênc. Agrár. Ambient., Curitiba, v. 6, n. 3, p. 401-411, jul./ set. 2008 


\section{INTRODUÇÃO}

O crescimento fúngico e a subsequente contaminação de alimentos animais e humanos por micotoxinas representam tanto risco econômico quanto para a saúde humana e animal. As micotoxinas de maior preocupação para a saúde animal e humana são produzidas por três principais gêneros de fungos (A spergillus, Fusarium e Penicillium). As fumonisinas, produzidas pelo Fusarium moniliforme e pelo $\mathrm{F}$. proliferatum, são uma família de micotoxinas que podem contaminar alimentos, predominantemente aqueles à base de milho (TURNER; NIKIEMA; WILD, 1999).

Relatos de ocorrência natural de fumonisinas com alto nível têm sido obtidos em milho (200 $\mathrm{mg} / \mathrm{kg}$ ) e induzem leucoencefalomalácia equina e edema pulmonar em suínos (NORRED, 1993; BAILLY et al., 1996). Em espécies aviárias, as fumonisinas têm associação com performances reduzidas, aumento no peso de órgãos e hepatite ou hiperplasia hepatocelular em frangos de corte, perus e patos (BROWN; ROTTING HAUS; WILLIAMS, 1992; LED OUX et al., 1992a; WEIBKING et al., 1993ab; ESPAD A et al., 1994, 1997; BERMUD EZ; LED OUX; RO TTING HAUS, 1995; ESPAD A et al., 1997). Além disso, a influência das fumonisinas sobre o sistema imune de aves também tem sido relatada (LI et al., 1999) e este fato pode comprometer a criação industrial de aves devido a essa imunossupressão aumentar a ocorrência de outras enfermidades.

Por outro lado, existe também a preocupação que seres humanos podem ser expostos às fumonisinas pelo consumo de produtos animais contaminados, como carne, leite e ovos (TURNER; NIKIEMA; WILD , 1999).

A seleção de modelos experimentais animais é crucial para relatar o risco que as fumonisinas proporcionam aos seres humanos. Turner, Nikiema e Wild (1999) destacam que, para obter informações úteis com relação aos riscos humanos, deve ser utilizada grande variedade de modelos animais in vivo e in vitro. Nesta revisão busca-se avaliar os principais efeitos das fumonisinas observados em diversos modelos animais, principalmente no que se refere ao sistema imunológico.

\section{MICOTOXINAS}

\section{Fumonisinas}

As fumonisinas, produzidas pelo Fusarium moniliforme e pelo F. proliferatum, fazem parte de uma família de micotoxinas que contaminam alimentos, predominantemente à base de milho, ao redor do mundo (TURNER; NIKIEMA; WILD, 1999).

A fumonisina $B_{1}$ é o principal metabólito produzido pelos fungos F usarium moniliforme e $F$. proliferatum, os quais são achados como contaminantes difundidos no milho (GELDERBLOM et al., 1992), sendo o metabólito mais abundante e mais tóxico deste grupo de micotoxinas, representando $70 \%$ da concentração to tal em rações e alimentos naturalmente contaminados, seguido pelas fumonisinas B2 e B3 (MURPHY; RICE; ROSS, 1993; NORRED, 1993).

\section{Mecanismo de ação das fumonisinas}

O mecanismo de ação das fumonisinas ainda não é bem descrito, mas vias bioquímicas de sua ação têm sido propostas para explicar as doenças animais induzidas por estas micotoxinas, como a inibição da biossíntese dos esfingolipídeos (NORRED , 1993), que são importantes para a integridade e a atividade fisiológica celular, sendo encontrados em altas concentrações no cérebro e no tecido nervoso de mamíferos e aves (SANTIN, 2000). As fumonisinas também afetam outros aspectos do metabolismo lipídico e centros de regulação celular, como a biossíntese de eicosanoides, como demonstrado por G elderblom et al. $(1996,1997)$. Mais recentemente, danos oxidativos que ocorrem nas células e D NA foram descritos em ratos (ABEL; GELDERBLOM, 1998; SAHU et al., 1998; YIN et al., 1998). 


\section{SISTEMA IMUNE AVIÁRIO}

\section{Resposta imunológica}

A capacidade do organismo em reagir a agentes estranhos é denominada resposta imunológica (KO UTSO S; KLASING, 2001; MORGULIS, 2002). Vários fatores podem influenciar a resposta imunológica, incluindo as variações genéticas de isolados distintos de uma mesma espécie de patógeno e da genética da própria ave (MO RRIS et al., 2004). Para o seu desencadeamento, o organismo das aves conta com uma série de componentes celulares e não celulares, os quais, por sua vez, são capazes de produzir um número muito grande de substâncias responsáveis pelas mais diversas funções.

A resposta imunológica do tipo primária apresenta baixa especificidade, capacidade limitada de modos de ação e memória nula, enquanto a resposta do tipo secundária age de maneira inversa, complementando a anterior e com a característica de ser específica (BUTCHER; MILES, 2003). A resposta do tipo primária envolve a participação de componentes celulares (fagócitos e células NK), barreiras físicas (pele, muco) e proteínas (sistema complemento). A resposta secundária envolve principalmente linfócitos e atuação de anticorpos.

A reação inflamatória, que é uma resposta imunológica, apresenta nas aves algumas diferenças em relação aos mamíferos, tais como: 0 aumento de permeabilidade não atinge os capilares, restringindo-se às vênulas; mediadores como a histamina e a serotonina estão presentes, mas outros, como a bradicinina, não parecem ter a mesma relevância; a migração celular é mais tardia e a atividade concomitante de heterófilos, monócitos e basófilos parece ser uma característica mais própria das aves do que dos mamíferos (MORG ULIS, 2002).

\section{Óngãos do sistema imune}

O sistema imune das aves funciona de maneira muito semelhante ao dos mamíferos (VAINIO ; IMHOF, 1995), porém, a estrutura e diferenciação dos órgãos linfoides nas aves apresentam diferenças quando comparadas às dos mamíferos.

\section{Órgãos linfoides primários}

$\mathrm{O}$ frango, originado de cruzamentos de linhagens de $\mathrm{G}$ allus gallus, não apresenta linfonodos. Da mesma forma, as aves apresentam um órgão único, a Bursa de Fabricius. Na galinha, o timo apresenta-se na forma de dois cordões de sete lobos cada, dispostos paralelamente ao longo das jugulares. Também, nessa espécie, é encontrada uma concentração de tecido linfoide na região oculonasal, denominada glândula de Harder (MORG ULIS, 2002).

Ó rgãos que regulam a produção e a diferenciação de linfócitos são os órgãos linfoides primários. Os linfócitos maduros encaixam-se em duas populações principais: as células $\mathrm{T}$ e as células $\mathrm{B}$, dependendo de qual órgão linfoide amadureceram (TIZARD , 2002). As células T amadurecem no timo, órgão encontrado tanto nos mamíferos como nas aves. Já, as células B, nas aves, amadurecem na Bursa de Fabricius.

0 timo localiza-se no mediastino anterior e seu tamanho varia consideravelmente, sendo seu peso relativo maior no animal recém-nascido e seu peso absoluto maior na puberdade (TIZARD , 2002). 0 córtex do timo encontra-se densamente infiltrado com linfócitos, mas na parte interna, a medula contém poucos linfócitos, apresentando muitas células epiteliais.

As células $\mathrm{T}$, liberadas do timo para a circulação, devem ser capazes de participar de respostas imunes, mas para isso devem antes passar por uma seleção positiva e negativa. 0 corre uma apoptose na medula do timo, resultando na destruição seletiva de células que reconhecem complexos de peptídeo-MHC (Major Histocompatibility Complex) de classe II com alta afinidade, e estas poderiam, potencialmente, causar uma doença autoimune se escapassem para a periferia. As células $\mathrm{T}$ em desenvolvimento, que sobreviveram à seleção negativa, reconhecem e processam complexos específicos 
de peptídeo próprio-MHC de classe II com moderada afinidade e são subsequentemente destinadas a crescer no córtex tímico, processo este chamado de seleção positiva. Essas células eventualmente deixam o timo para formar grupos de células T (TIZARD , 2002).

A bursa de Fabricius consiste de um saco redondo localizado imediatamente acima da cloaca. Como o timo, a bursa consiste em linfócitos incrustados em tecido epitelial. A bursa serve de local para maturação e diferenciação para as células do sistema formador de anticorpos, chamadas de células B. Nos mamíferos, esse papel é desempenhado pela medula óssea. (TIZARD , 2002).

\section{Órgãos linfoides secundários}

O baço das aves apresenta forma arredondada, filtra os antígenos a partir do sangue. Esse processo de filtração remove tanto partículas antígenas como células sanguíneas envelhecidas. Portanto, o baço é dividido em dois compartimentos: um para armazenamento de eritrócitos, captura de antígenos e armazenamento de hemácias, chamado polpa vermelha, e um, rico em linfócitos, onde ocorrem as respostas imunes, conhecido como polpa branca (TIZARD, 2002).

As estruturas linfoides encontradas no trato gastrintestinal também são consideradas órgãos linfoides secundários, representando parte importante do sistema imune das aves, principalmente devido ao fato de existirem inúmeros patógenos que podem estar presentes na luz do tubo digestivo.

As placas de Peyer são agregadas linfoides presentes no intestino. Nas galinhas, as placas de Peyer estão localizadas principalmente na porção mais distal do íleo e possuem algumas peculiaridades histológicas, como um maior achatamento do epitélio intestinal que as recobre, ausência de células caliciformes e um maior espessamento ao nível da estrutura das vilosidades intestinais que as revestem (TOIVANEN; TOIVANEN, 1987).

As tonsilas cecais se constituem na massa de tecido linfoide mais concentrada do intestino, sendo composta de duas áreas ovais situadas na entrada dos cecos. As tonsilas não estão presentes logo após o nascimento, e o seu aparecimento e desenvolvimento dependem, estreitamente, de estímulos antigênicos produzidos ao nível da mucosa intestinal (MONTASSIER, 2000).

Há ainda outra estrutura anátomo-histológica linfoide do trato intestinal das galinhas, 0 divertículo de Meckel. São encontradas grandes quantidades de plasmócitos desenvolvidos a partir de linfócitos B aí presentes, que sofrem estímulos antigênicos, semelhantemente ao que ocorre na glândula de Harder (OLAH; GLICK; TAYLOR,1984).

O sistema GALT, que é um tecido linfoide associado aos intestinos das aves, tem como papel ser o sítio de ocorrência de maturação de linfócitos e respostas inflamatórias locais (CALDWELL et al., 2004).

Além dos tecidos linfoides associado ao trato intestinal, as aves apresentam um tecido linfoide paraocular e paranasal, agregado à glândula de Harder. Esse tecido linfoide é considerado responsável pelas respostas imunes locais que ocorrem nas mucosas ocular, nasal e de outras áreas do trato respiratório superior (MONTASSIER, 2000).

\section{Células do sistema imune}

As células do sistema imune das aves dividem-se de acordo com sua morfologia nuclear.

\section{Agranulócitos}

Os linfócitos do frango apresentam aproximadamente o mesmo tamanho que os dos mamíferos. São células arredondadas e de contorno irregular, com o núcleo geralmente localizado no centro da célula (MORG ULIS, 2002).

$O$ reconhecimento do antígeno pelos linfócitos $\mathrm{B}$ e $\mathrm{T}$ se faz de maneiras diferentes. Os linfócitos B reconhecem os antígenos utilizando imunoglobulinas de alta especificidade e expressas em sua superfície e capazes de reconhecer agentes antigênicos íntegros. Já os linfócitos T não são capazes de reconhecer 0 antígeno sozinho. Eles necessitam de componentes auxiliares para atuar contra agentes agressores, as células apresentadoras de antígenos (APC), (MORG ULIS, 2002). 
Os linfócitos T podem ser classificados ainda em outras subpopulações: os linfócitos T auxiliares ("helpers") e os linfócitos T citotóxicos, de acordo com sua função dentro do mecanismo de resposta imunológica. Os linfócitos $\mathrm{T}$ auxiliares são células que secretam citocinas e ativam os mecanismos de defesa executados pelos macrófagos, responsáveis pela eliminação de agentes previamente fagocitados. Têm um importante papel na imunidade adquirida, tanto em aves quanto em mamíferos. Já os linfócitos $\mathrm{T}$ citotóxicos atuam na resposta imunológica mediada por células e têm como alvos principais as células que se apresentam alteradas, como aquelas que hospedam qualquer tipo de antígeno, mesmo de origem endógena. Também liberam citocinas que ativam macrófagos, estimulando a atividade de eliminação de antígenos por mecanismos oxidativos (ERF, 2004).

Os linfócitos B são responsáveis pela produção de anticorpos no organismo das aves, moléculas que atuam impedindo a invasão das células por antígenos externos ou internos. Nas aves, são produzidos no fígado do embrião, no saco vitelínico e na medula óssea na fase inicial da incubação. Em seguida, migram para a bursa de Fabricius, onde sofrem amadurecimento e diferenciação por até dez semanas. A partir do 160 dia de incubação migram para colonizar outros órgãos, como o baço e a glândula de Harder (BUTCHER; MILES, 2003). Na Bolsa ocorre um fenômeno denominado conversão gênica que permite aos linfócitos B produzirem uma gama mais variada de anticorpos, expressos em sua superfície (DIETERT; LAMONT, 1994).

As células Natural Killer (NK) são subpopulações de linfócitos capazes de matar células tumorais e de mediar a imunidade contra células infectadas por vírus. Sharma (1981) demonstrou que as células NK têm atividade contra tumores e agentes infecciosos. Uma grande diferença entre as células NK de aves e mamíferos é a localização destas células no organismo. Enquanto em mamíferos elas são abundantes no sangue periférico, em aves elas surgem de forma muito mais frequente no epitélio intestinal (GÖBEL; KASPERS; STANGASSINGER, 2001).

O s macrófagos são considerados a primeira linha de defesa contra agentes infecciosos, sendo fundamentais na regulação da resposta imune, tanto natural, quanto específica (KLASING, 1998; QURESHI, 1998). E stão distribuídos em todo o organismo, e são capazes de fagocitar partículas estranhas e destruí-las sem haver necessidade de transcorrer muito tempo após o encontro. Além disto, são capazes de secretar citocinas, substâncias que exercem papel regulatório na resposta imunológica. Os monócitos são as células da linhagem monocítica presentes no sangue das aves e que também possuem capacidade de fagocitar partículas estranhas, mas que possuem pouca capacidade regulatória (MORG ULIS, 2002). Os macrófagos provêm da mesma linhagem celular dos monócitos, mas estão presentes nos tecidos.

O s trombócitos das aves possuem atividade fagocítica bastante intensa. Possuem um grande número de lisossomas, o que sugere grande capacidade de ação de destruição de antígenos por digestão enzimática, sendo por isso importante na imunidade das aves contra vários patógenos que poderão alcançar a corrente sanguínea (MO RG ULIS, 2002).

\section{Granulócitos}

Nas aves, os heterófilos são análogos aos neutrófilos dos mamíferos. A principal função dos heterófilos é a fagocitose, que se realiza como resposta a um estímulo quimiotático. Esses fagócitos são importantes mediadores da imunidade natural das aves, especialmente nas jovens, que ainda não desenvolveram completamente a imunidade adquirida (MO RG ULIS, 2002). O s heterófilos são muito importantes na inflamação e na imunidade das aves (HARMO N, 1998). O s heterófilos são ativados por citocinas e, possivelmente, outros mediadores químicos que promovem um aumento de sua capacidade fagocítica (MORG ULIS, 2002).

Os eosinófilos possuem mecanismo desintoxicante e são importantes na regulação do processo inflamatório. Os eosinófilos não são propriamente fagócitos, eles atuam na membrana plasmática da célula infectada e por degranulação, liberando seus grânulos que contêm histaminase que inibe a histamina encontrada nos basófilos e mastócitos, moderando assim as reações anafiláticas. $\mathrm{Na}$ reação imunológica não são encontrados eosinófilos, indicando que as aves não reagem da mesma forma ao estímulo imunológico que os mamíferos (MORG ULIS, 2002). 
Os basófilos encontram-se no sangue periférico e aumentam em processos necróticos, etapas iniciais da inflamação, reações de hipersensibilidade e situações de estresse severo em aves, aonde promovem uma liberação maciça do conteúdo de seus grânulos, que é rico em mediadores da resposta imunológica, como a histamina (MORG ULIS, 2002).

\section{Componentes não celulares do sistema imune}

Os anticorpos, também chamados de imunoglobulinas, são produzidos por células B e são fundamentais na imunidade das aves contra diversas infecções. Para atuar, os anticorpos unem-se diretamente à molécula de antígeno ou ativam o sistema complemento. Ao se ligarem diretamente ao antígeno, os anticorpos podem fazer com que haja aglutinação de partículas grandes, formando um aglomerado. Podem fazer, também, com que haja precipitação do complexo antígeno-anticorpo, formando um composto insolúvel. Podem também ligar-se a porções importantes do antígeno, fazendo com que este perca sua patogenicidade. A ligação do anticorpo com 0 antígeno facilita 0 englobamento pelos fagócitos e, da mesma forma, ao se ligarem às células os anticorpos podem causar ruptura e lise celular, eliminando células que apresentem antígenos conhecidos. (MO RG ULIS, 2002).

As citocinas exercem um papel fundamental na formação e modulação da resposta imunológica, e são mediadoras de ação local e sistêmica. Uma mesma citocina pode ser produzida por diferentes tipos celulares e, da mesma forma, uma única citocina pode atuar em diferentes células, (MO RGULIS, 2002). À medida que se conhece melhor a natureza das citocinas, percebe-se sua importância, principalmente em situações de formação de resposta celular contra agentes intracelulares, sobre os quais as imunoglobulinas (resposta sistêmica) não possuem ação efetiva (LILLEHOJ; MIN; D ALLO UL, 2004).

As citocinas têm um grande potencial para a produção de aves, já que participam e regulam uma série de processos fundamentais dentro da fisiologia aviária, como a resistência às doenças, a cicatrização, o metabolismo ósseo, o crescimento, o apetite e a reprodução (KLASING , 1994).

O sistema complemento é um conjunto de proteínas, muitas delas precursoras de enzimas, presentes no plasma. Podem ser ativadas através de duas vias: a via clássica e a alternativa. Uma vez ativadas, exercem seu papel dentro do sistema imunológico desencadeando reações de natureza enzimática que geram outras substâncias importantes para a formação da resposta imunológica. Na via clássica, a ativação das proteínas do sistema complemento se dá pela ligação de uma proteína, C1, do complemento com uma porção do anticorpo ligado ao antígeno. Isso leva a uma série de reações em cascata com formação de vários elementos com diferentes atividades na imunidade, como fagocitose e quimiotaxia pelo local onde se encontra 0 antígeno. A via alternativa ocorre sem que haja a necessidade da formação do complexo antígeno-anticorpo (MORG ULIS, 2002).

\section{INTERAÇÃO ENTRE MICOTOXINAS E IMUNIDADE}

Tanto a imunidade inata como a adquirida pode ser afetada pelas micotoxinas. Um aspecto que pode ilustrar muito bem esse fato é o efeito das micotoxinas sobre o epitélio intestinal, já que essa mucosa é considerada uma barreira física contra patógenos, possuindo, ao mesmo tempo, componentes da imunidade inata quanto especifica como é o caso da presença de linfócitos e IgA. Na realidade, logo na ingestão de um alimento contaminado, as células da mucosa intestinal podem ficar expostas a grandes concentrações dessas toxinas (PRELUSKY et al., 1996). Como é descrito por Bouhet e O swald (2005), a função de barreira física realizada pelo epitélio intestinal é conseguida através da resistência elétrica trans-epitelial (TEER), que existe na monocamada celular. Algumas toxinas são capazes de diminuir essa TEER em células do intestino de humanos como ocratoxina, patulina e deoxinivalenol. Bouhet et al. (2004) assinalaram que as fumonisinas também alteram essa resistência trans-epitelial nas células do intestino de suínos, podendo ser essa uma explicação dos processos de injúria, descamação e ulceração observados em animais expostos à ingestão de micotoxinas. 
Vários investigadores procuraram explicar qual o mecanismo pelo qual as micotoxinas poderiam afetar essa TEER na mucosa intestinal. Mclaughlin et al. (2004) explicam que isso possa acontecer devido à diminuição na quantidade de proteínas que estão nas junções celulares e, de acordo com Leung et al. (2003), a diminuição na biossíntese de esfingolipídios que é inibida pelas fumonisinas pode alterar a regulação elétrica das células epiteliais.

Por outro lado, as células da mucosa intestinal que fazem essa proteção física inata é um tecido que está em constante renovação para manter a integridade deste epitélio, o que ocorre a partir da proliferação de células indiferenciadas provenientes da cripta e que se diferenciam e se deslocam ao longo das vilosidades, sendo eliminadas por extrusão no ápice do vilo intestinal. Micotoxinas como T2 (LI et al., 1999) e ocratoxina (ALBASSAM et al., 1987) induzem necrose das células epiteliais da cripta provocando atrofia de vilosidades. Fumonisinas são descritas como bloqueadoras das fases mitóticas do ciclo das células epiteliais diminuindo sua proliferação (BO UHET et al., 2004), e baixas doses de D eoxinivalenol (D O N) interferem sobre a diferenciação de enterócitos (KASUGA et al., 1998).

Ainda no que se refere à imunidade inata da mucosa intestinal, sabe-se que a produção de muco a partir das células caliciformes tem importante função como lubrificação e barreira protetora deste epitélio. Sabe-se que quando a mucosa intestinal sofre desafios ocorre incremento no número destas células no intestino com aumento na produção de muco. Entretanto, um estudo na literatura demonstra que fumonisina induz hiperplasia de células epiteliais da mucosa intestinal de frangos de corte (BROWN; ROTTINGHAUS; WILLIAMS, 1992), e mais estudos nesse aspecto são necessários para verificar a influência desta e de outras micotoxinas sobre a proliferação de células caliciformes e a produção de muco.

$\mathrm{Na}$ imunidade específica de mucosa destacam-se o papel das imunoglobulinas e células imunes como linfócitos T. Em mamíferos, $80-90 \%$ das imunoglobulinas presentes nos fluidos intestinais, lágrimas e glândulas parótidas são IgA (BUTLER et al., 2006). D e acordo com revisão de Bouhet e O swald (2005), a toxina T-2 suprime as células B nas placas de Peyer, mas o efeito direto sobre a produção de IgA não foi investigado. Por outro lado, Petska et al. (2004) afirmam que outros tricotecenos como D O N e nivalenol provocam uma dramática elevação na produção de IgA em ratos, a ponto do acúmulo desses anticorpos causar nefropatia ocasionando hematúria como consequência.

O utro aspecto afetado pelas micotoxinas é a produção de citocinas pelas células intestinais que desempenham papel fundamental no recrutamento de células inflamatórias para defesa desta mucosa. O swald et al. (2003) descreveram que leitões alimentados com baixos níveis de fumonisina diminuem a expressão de IL-8 no íleo, sugerindo que esse fato pode ter grande influência na maior susceptibilidade à E. coli observada nesses animais quando comparado ao grupo controle. Aqueles autores sugerem que esse menor recrutamento de células inflamatórias ocasionado pela diminuição na expressão de IL-8 se associa à ação dessa toxina na redução de proliferação celular e integridade da mucosa do intestino aumentando a susceptibilidade dos animais à colonização bacteriana.

A interferência de micotoxinas na defesa das mucosas também foi descrita sobre a funcionalidade de macrófagos alveolares em suínos. Liu et al. (2002) demonstraram que tanto fumonisina $B_{1}$ quanto aflatoxina apresentam citotoxicidade dose e tempo dependentes para macrófagos alveolares de suínos, porém, a partir de alterações distintas, uma vez que são metabólitos totalmente diferentes. Fumonisina $\mathrm{B}_{1}$ inibe a esfingosina e esfingosina- $\mathrm{N}$-acetiltransferase, que são fundamentais para a rota "de novo" de síntese de esfingolipídios, e este é descrito como um evento inicial da citotoxicidade da fumonisina em células. Alguns estudos demonstram que a toxicidade da fumonisina para macrófagos de aves (Q URESHI; HAG LER, 1992) é maior de que a observada em suínos (LIU et al., 2002) sugerindo uma diferença entre as espécies animais quanto à sensibilidade a essa micotoxina.

A influência desses metabólitos tóxicos de fungos na imunidade das mucosas pode afetar muito o desempenho animal, já que a indução dessa imunidade é muito importante para conferir proteção contra diversos patógenos que, tipicamente, invadem essas superfícies. Em adição, existe aparentemente uma inter-relação entre as distintas mucosas do organismo, o que permite que a estimulação de uma superfície mucosa potencialmente induza proteção específica em outras mucosas (STREATFIELD , 2006). Como a administração de vacinas via oral também é uma rota bastante prática e econômica de imunização dos animais, quando ocorre a interferência de micotoxinas nessa resposta 
imune, 0 resultado da vacinação pode ser afetado.

Estudos em ratos também apresentaram que o efeito da fumonisina sobre a resposta a imunização com SRBC (Sheep Red Blood Cells) depende do momento da administração da toxina sendo seu efeito evidente somente se a imunização ocorrer concomitantemente com a vacinação (TRY PHO NAS et al., 1997). Aqueles autores também admitiram que somente os machos, e não as fêmeas, tiveram sua imunidade humoral afetada pela fumonisina.

Na verdade, todas essas alterações descritas na literatura comprovam que as micotoxinas alteram a resposta imune dos animais, podendo interferir com a resposta vacinal e deixar os animais suscetíveis a infecções inespecíficas, ou mesmo para aquelas contra as quais esses animais tenham sido vacinados.

\section{CONSIDERAÇÕES FINAIS}

A avicultura brasileira está em crescente expansão no mercado mundial e a cada momento tem que se adequar às exigências do mercado. Para manter seu status, estudos são focados na nutrição animal, visando um menor custo de produção com maior eficiência. 0 decréscimo do uso de aditivos antimicrobianos nas rações tem exigido maiores estudos em relação às particularidades imunológicas das aves. D essa maneira, tem-se estimulado a busca pela prevenção de possíveis agressões ao sistema imune desses animais, sempre na busca pela otimização de seu desempenho e produção.

Com isso, ressalta-se a importância do estudo da fumonisina na cadeia de produção de frango de corte, desde a colheita até o arraçoamento desses animais, e garantindo-se, o controle dessa micotoxina estabelecer-se-á condições de manter a produção em elevada escala.

\section{REFERÊNCIAS}

ABEL, S.; G ELD ERBLO M, W. C. Oxidative damage and fumonisin B1-induced toxicity in primary rat hepatocytes and rat liver in vivo. Toxicology, v. 131, p. 121-131, 1998.

ALBASSAM, M. et al. Histopathologic and electron microscopic studies on the acute toxicity of ochratoxin A in rats. Veterinary Pathology, v. 24, n. 5, p. 427-435, 1987.

BAILLY, J. D. et al. Leucoencephalomalacie des équide's: cas rapporte's au CNITV. Revista Científica de Medicina Veterinária, v. 147, p. 787-796, 1996.

BERMUDEZ, A. J.; LEDOUX, D. R.; ROTTINGHAUS, G. E. Effects of F usarium moniliforme culture material containing known levels of fumonisin B1 in ducklings. Avian D iseases, v. 39, n. 4, p. 879-886, 1995.

BOUHET, S. et al. The mycotoxin fumonisin B1 alters the proliferation and the barrier function of porcine intestinal cells. Toxicological Sciences, v. 77, n. 1, p. 165-171, 2004.

BO UHET, S.; O SWALD, I. P. The effects of mycotoxins, fungal food contaminants, on the intestinal epithelial cell-derived innate immune response. Veterinary Immunology and Immunopathology, v. 108, n. 1-2, p. 199-209, 2005.

BROWN, T. P.; ROTTING HAUS, G. E.; WILLIAMS, M. E. Fumonisin mycotoxicosis in broilers: performance and pathology. Avian Diseases, v. 36, n. 2, p. 450-454, 1992.

BUTCHER, G. D.; MILES, R. D. Avian immune system: veterinary medicine - large animals clinical sciences Departament, Florida Cooperative Extension Service, Institute of Food and Agricultural Sciences. University of Florida. IFAS, 2003. v. 74. 
BUTLER, J. E. et al. Antibody repertoire development in swine. Development and Comparative Immunology, v. 30, n. 1-2, p. 199-221, 2006.

CALDWELL, D. J. et al. Participation of the intestinal epithelium and mast cells in local mucosal immune responses in commercial poultry. Poultry Science, v. 83, n. 4, p. 591-599, 2004.

DIETERT, R. R.; LAMONT, S. J. Symposium: current advances in avian immunology: avian immunology: from fundamental immune mechanisms to integrative management of poultry. Poultry Science, v. 73, n. 7, p. 975-978, 1994.

ERF, G. F. Cell-mediated immunity in poultry. Poultry Science, v. 83, n. 4, p. 580-590, 2004.

ESPADA, Y. et al. Fumonisin mycotoxicosis in broilers. Weights and serum chemistry modifications. Avian Diseases, v. 38, n. 3, p. 454-460, 1994.

ESPADA, Y. et al. Fumonisin mycotoxicosis in broilers: plasma proteins and coagulation modifications. Avian Diseases, v. 41, n. 1, p. 73-79, 1997.

GELDERBLOM, W. C. et al. Fumonisins: isolation, chemical characterization and biological effects. Mycopathology, v. 117, n. 1-2, p. 11-16, 1992.

. Effect of fumonisin B1 on protein and lipid synthesis in primary rat hepatocytes. Food ànd Chemical Toxicology, v. 34, n. 4, p. 361-369, 1996.

. Effect of fumonisin B1 on the levels and fatty acid composition of selected lipids in rat liver in vivo. Food and Chemical Toxicology, v. 35, n. 7, p. 647-656, 1997.

GÖBEL, T. W.; KASPERS, B.; STANGASSINGER, M. NK and T cells constitute two major, functionally distinct intestinal epithelial lymphocyte subsets in the chicken. International Immunology, v. 13, n. 6, p. 757-762, 2001.

HARMON, B. G. Avian heterophils in inflammation and disease resistance. Poultry Science, v. 77, n. 7, p. 972-977, 1998.

KASUGA, F. et al. In vitro effect of deoxynivalenol on the differentiation of human of human colonic cell lines caco-2 and T84. Mycopathology, v. 142, n. 3, p. 161-167, 1998.

KLASING, K. C. Symposium: current advances in avian immunology. Avian leukocytic cytokines. Poultry Science, v. 73, n. 7, p. 1035-1043, 1994.

. Avian macrophages: regulators of local and systemic immune responses. Poultry Science, $\overline{\mathrm{v}}^{-} \overline{7} \overline{7}, \overline{\mathrm{n}} . \mathbf{7}, \mathrm{p} .983-989,1998$.

KOUTSO S, E. A.; KLASING, K. C. Interactions between the immune system, nutrition and productivity of animals. In: Recent Advances in Animal Nutrition 2001. Nottingham: University Press, 2001. p. 173-190.

LED OUX, D. R. et al. Fumonisin toxicity in broiler chicks. Journal of Veterinary Diagnostic Investigation, v. 4, n. 3, p. 330-333, 1992a.

. Effects of Fusarium moniliforme culture material containing known levels of fumonisim B------1 on turkey poults. Poultry Science, v. 71, suppl. 1, p. 162, $1992 \mathrm{~b}$.

LEUNG, L. W. et al. Inhibitors of glycosphingolipid biosynthesis reduce transpithelial electrical resistance in MD CK I and FRT cells. Amenican Journal of Physiology - Cell Physiology, v. 284, n. 4, p. 1021-1030, 2003.

LI, Y. C. et al. Effects of fumonisin B1 on selected immune responses in broiler chicks. Poultry Science, v. 78, n. 9, p. 1275-1282, 1999. 
LILLEHOJ, H. S.; MIN, W.; DALLOUL, R. A. Recent progress on the cytokine regulations of intestinal responses to Eimeria. Poultry Science, v. 83, n. 4, p. 611-623, 2004.

LIU, B. H. et al. The effects of mycotoxins, fumonisin B1 and aflatoxin B1, on primary swine alveolar macrophages. Toxicology and Applied Pharmacology, v. 180, n. 3, p. 197-204, 2002.

MCLAUG HLIN, J. et al. O chratoxin A increases permeability through tight junctions by removal of specific claudin isoforms. American Journal of Physiology - Cell Physiology, v. 287, p. 1412-1417, 2004.

MO NTASSIER, H. J. Enfermidades do sistema imune. In: BERCHIERI, A.; MACARI, M. Doenças das aves. Campinas: Facta, 2000. p. 133-150.

MORG ULIS, M. S. Imunologia aplicada. In: MACARI, M.; FURLAN, R. L.; GONZALES, E. Fisiologia aviária aplicada a frangos de corte. Jaboticabal: FUNEP, 2002. p. 231-245.

MO RRIS, B. C. et al. Intestinal mucosal mast cell immune response and pathogenesis of two E imeria acervulina isolates in broiler chickens. Poultry Science, v. 83, n. 10, p. 1667-1674, 2004.

MURPHY, P. A.; RICE, L. G.; RO SS, P. F. Fumonisin B1, B2 and B3 content of Iowa, Wisconsin, and Illinois corn and corn screenings. Journal of Agricultural and Food Chemistry, v. 41, n. 2, p. 263-266, 1993.

NORRED, W. P. Fumonisins: mycotoxins produced by Fusarium moniliforme. Journal Toxicology Environmental H ealth, v. 38, n. 3, p. 309-328, 1993.

NORRED, W. P.; VOSS, K. A. Toxicity and role of fumonisins in animal diseases and human esophageal cancer. Journal of Food Protection, v. 57, n. 6, p. 522-527, 1994.

OLAH, I.; GLICK, B.; TAYLOR, R. L. Meckel's diverticulum. II. A novel limphoepthelial organ in the chicken. The Anatomical Record, v. 208, n. 2, p. 253-263, 1984.

O SWALD, I. P. et al. Mycotoxin fumonisin B1 increases intestinal colonization by pathogenic Escherichia coli in pigs. Applied and Environmental Microbiology, v. 69, n. 10, p. 5870-5874, 2003.

PESTKA, J. J. et al. Cellular and molecular mechanism for immune modulation by deoxynivalenol and other trichothecenes: unraveling a paradox. Toxicology Letters, v. 153, n. 1, p. 61-73, 2004.

PRELUSKY, D. B. et al. Biological fate on fumonisin B1 in food-producing animals. Advances in Experimental Medicine and Biology, v. 392, p. 265-278, 1996.

QURESHI, M. A.; HANGLER Jr., W. M. Effect of fumonisin B----- on chicken macrophage functions in vitro. Poultry Science, v. 71, p. 102-104, 1992.

QURESHI, M. A. Role of macrophages in avian health and disease. Poultry Science, v. 77, n. 7, p. 978-982, 1998.

SAHU, S. C. et al. Peroxidation of membrane lipids and oxidative DNA damage by fumonisin B1 in isolated rat liver nuclei. Cancer Letters, v. 125, p. 117-121, 1998.

SANTIN, E. Micotoxicoses. In: BERCHIERI Jr., A.; MACARI, M. Doenças das aves. Campinas: Facta, 2000. p. 379-388.

SHARMA, J. Natural killer activity in chickens exposed to Marek's disease virus: inhibition of activity in the susceptible chickens and enhancement of activity resistant and vaccinated chickens. Avian Diseases, v. 25, n. 4, p. 882-893, 1981.

STREATFIE LD, S. J. Mucosal immunization using recombinant plant-based oral vaccine. Methods, v. 38, n. 2, p. 150-157, 2006. 
SYD ENHAM, E. W. et al. Natural occurrence of some F usarium mycotoxin maize from high and low eosophageal cancer prevalence areas of the Transkei, southern Africa. Journal of Agricultural and Food Chemistry, v. 38, p. 1900-1903, 1990.

TIZARD, I. R. Imunologia veterinária: uma introdução. 6. ed. São Paulo: Roca, 2002.

TOIVANEN, A.; TOIVANEN, P. Avian immunology: basis and practice. Boca Raton: CRC PRESS, 1987. v. 1, 2.

TRYPHONAS, H. et al. Effects of fumonisin B1 on the immune system of sprague-dawley rats following a 14-day oral (gavage) exposure. Fundamental and Applied Toxicology, v. 39, p. 5359, 1997.

TURNER, P. C.; NIKIEMA, P.; WILD, C. P. Fumonisin contamination of food: progress in development of biomarkers to better assess human health risks. Mutation Research, v. 443, p. 8193, 1999.

VAINIO, O.; IMHOF, B. A. The immunology and developmental biology of the chicken. Immunology Today, v. 6, n. 8, p. 365-370, 1995.

WEIBKING, T. S. et al. Effects of feeding Fusarium moniliforme culture material, containing known levels of fumonisin B1, on the young broiler chick. Poultry Science, v. 72, p. 456-466, 1993a.

Fumonisin toxicity in turkey poults. Journal of Veterinary Diagnostic and Investigation, v. 5, p. 75-83, 1993b.

WEIBKING, T. S. Individual and combined effects of feeding F usarium moniliforme culture material, containing known levels of fumonisin B1, and aflatoxin B1 in the young Turkey poult. Poultry Science, v. 73, p. 1517-1525, 1994.

YIN, J. J. et al. Effects of fumonisin B1 on lipid peroxidation in membranes. Biochimica et Biophysica Acta, v. 1371, n. 1, p. 134-142, 1998.

Recebido: 19/ 03/ 2008 Received: 03/ 19/ 2008

Aprovado: 14/ 04/ 2008

A pproved: 04/ 14/ 2008 